\title{
Quantifying the Mean Sea Level Change at the Gulf of Finland Coast Caused by the Realistic Portion of the Global Warming Forcing
}

\author{
Ali Bassal Mahmood \\ Institute of Marine and Coastal Sciences, University of Szczecin, Szczecin 70-383, Poland
}

\begin{abstract}
Quantifying the coastal mean sea level change causing by the winter positive phase of the North Atlantic oscillation index $\mathrm{NAO}+$ at the Gulf of Finland coast is of high priority for detecting and predicting the global warming impact in this region. Both boreal winter months and season of three long-term data station series of the coastal mean sea levels and the NAO indices were linked for two cases, i.e.: different periods and the 1977-1994 period. This study is dedicated to: (1) Detecting the exclusive impacts of the NAO+; (2) Estimating the significant standard bivariate linear regression models; (3) Calculating the climatic linear trend coefficient by using three methods (OLS, GLS, Theil-Sen); (4) Correcting the mean sea level series anomalies by using the significant linear regression equations as a function of NAO+ anomalies, over the period 1977-1994; (5) Calculating the realistic linear trend caused as a function of NAO+ for period 1977-1994 in the context of the realistic portion of the global warming. The results reveal that, the $\mathrm{NAO}+$ manifests their impacts on the coastal mean sea levels and its contribution in the configured linear trends. The realistic linear changes have detected and predicted. The Gulf of Finland coast showed the warmest regions in the context of the realistic portion of the global warming during the winters of the period 1977-1994.
\end{abstract}

Key words: North Atlantic Oscillation, Gulf of Finland, mean sae level changes.

\section{Introduction}

The anthropogenic climate change is very complex process, varies regionally, and refers to the production of greenhouse gases emitted by human activity. Human activities result in emissions of four principal greenhouse gases: carbon dioxide $\mathrm{CO}_{2}$, methane $\mathrm{CH}_{4}$, $\mathrm{N}_{2} \mathrm{O}$ (nitrous oxide) and the halo carbons (a group of gases containing fluorine, chlorine and bromine), in which these gasses increased the global warming potential [1]. The global warming revealed through different oceanic-atmospheric processes in the Northern and Southern Hemispheres. Thompson et al. [2], confirmed the following points: (1) various indices in the $\mathrm{NH}$ (Northern Hemisphere) related to the AO (Arctic Oscillation) have exhibited a pronounced linear trend during the winter of the past 3 decades of the last century, which is reflected in

Corresponding author: Ali Bassal Mahmood, Ph.D., research field: physical oceanology. patterns of SLP (sea level pressure), geopotential height, precipitation, total column ozone, tropopause pressure, surface air temperature trends, strengthening of the westerlies at subpolar latitudes, and warming of the lower troposphere over Eurasia [2-7]; (2) different climate trends in the $\mathrm{NH}$ that pointed out by Hurrell [3, 4] what caused by the trend in the NAO (North Atlantic oscillation) index are consistent with the trend in the AO index; (3) these trends were consistent with model simulations of the response to increasing greenhouse gases and sulfate aerosols [8-11]. In particular, the recognition of the warming changes was predicted as a function of the winter positive phase of $\mathrm{NAO}+$ in the North Atlantic Ocean and in the continent between the latitudes $20^{\circ}-90^{\circ} \mathrm{N}$ of the $\mathrm{NH}$ by Hurrell [4]. Where, the realistic portion of the global warming was revealed also by the behavior of the NAO, which turned from the negative phase of NAO- index to the positive phase of $\mathrm{NAO}+$ index 
since the mid of 1970s [2-4], during the winters of the period 1977-1994 [4]. That is, the atmosphere is very active dynamically during the winter season and has largest perturbations amplitudes [12, 13].

Thus, the winter $\mathrm{NAO}+$ may affect the water cycle between land, sea, and air across many sectors of the economy, society, and the environment in the northern Europe.

So, the prominent impact of the NAO+ on the coastal mean sea levels at the Gulf of Finland coast is related with the economic life and population living along the coastlines. Thus, this impact should be detect and predict through analysis of the interrelation between the NAO and the coastal mean sea levels which is the most important step allows the realistic linear mean sea level change to predict as a function of NAO+ during the winters of the period 1977-1994 in the context of the realistic portion of the global warming considering this phase as a major forcing for mean sea level change.

The NAO is a measure of the ocean-atmosphere circulation at the surface and the only teleconnection pattern evident throughout the year in the NH [14] that can influence the local sea level in the Baltic Sea and the Gulf of Finland. During the winter, it accounts for more than one-third of the total variance in sea level pressure SLP over the North Atlantic [3, 4, 15-20].

There have been many studies concerning the detection of the influence of the NAO and estimation of the linear trend configured in the long-term mean sea level data series in Baltic Sea [21-24]. Nevertheless, most of the previous publications have not dealt quantitatively with the influence of the $\mathrm{NAO}+$ through the 1977-1994 period on the mean sea level in the Gulf of Finland. In contrast, one goal of the current study is to quantify the influence of this phase by estimating the configured trends, which have $\mathrm{NAO}+$ origins, in the present study by using statistical time series analysis technique in accordance with Hurrell [4], in which this kind of mean sea level is especially needed for detecting the impact of the global warming.
There are four main objectives representing the research hypotheses. The first is to detect the influence of boreal winter months and season of $\mathrm{NAO}+$ on the individual mean sea levels stations series over the whole period for each data station. The second is to estimate the relative linear mean sea level trend as a function of the climatic conditions after removing the VLM (vertical land movement), i.e. due to GIA (glacial isostatic adjustment) per each boreal winter months and season for the individual mean sea levels stations series. The third is to detect the influence of the boreal winter season of $\mathrm{NAO}+$ on the individual mean sea levels stations series over the period (1977-1994). The fourth is to predict the realistic linear mean sea level change as a function of the boreal winter season of $\mathrm{NAO}+$ over the period (1977-1994), for identifying the regional differences of the realistic portion of the global warming in term of $\mathrm{NAO}+$ at the study region.

The assessment for the outcome has been achieved for the boreal winter months DJF (i.e. the months of December, January, and February) and the boreal winter season DJF (the average of the months of December, January, and February months) timescales for each studied data station where the temperature gradients between Eurasia and North Atlantic were most pronounced through the period of the positive NAO+ within wintertime $[4,16,18,20]$.

The paper is organised as follows: following the introduction, the data sets used in this study and the methods applied in the analyses are described in Section 2. Then, Section 3 presents the results and discussion. Finally, conclusions are clarified in Section 4.

\section{Materials and Methods}

\subsection{Materials}

For the analysis, two different types of NAO indices were taken into account. The first was Jones' winter monthly mean NAO index for the 1824-2011 period, which represents the difference between 
normalised monthly mean SLP at Gibraltar and south-western Iceland. The data were collected from the website of the Climate Research Unit in Norwich, UK $[25,26]$. The second was Hurrell's winter season DJF mean NAO index for the 1865-2011 period, which represents the difference between normalised boreal winter season DJF mean SLP at Lisbon, Portugal and Stykkisholmur, Iceland. The data were collected from the website of the NCAR in Boulder, CO, USA $[3,12]$.

The mean sea level tide gauge data series were collected from Holgate et al. [27] and PSMSL [28]. Since tide gauge measure sea level relative to the land, they are in some parts of the Baltic Sea strongly influenced by vertical land movements VLM in response to glacial isostatic adjustment GIA. So, the linear trend in the sea level records, was caused by a combination of vertical land movement due to glacier isostatic adjustment GIA and other processes caused by climate variability (called the relative mean sea level) along the Baltic Sea coasts [29].

Then, the relative mean sea level trend $=$ isostatic trend + climatic trend, and assumed to be linear.

The OLS (Ordinary Least Square), GLS (Generalized Least Square Error Minimization), RSE (Robust Standard Error) and Theil-Sen techniques [4, 18, 29-45], could be used for estimating the individual linear trends, but these trends should be eliminated (linearly detrended) from the record before the correlation and regression calculations. In particular, the lands around the northern Baltic Sea are still rising from the last ice age due to postglacial rebound. This process also displays the linear trends that may caused by the long-term regional climate forcing, which have different physical origins Chen and Omstedt [22]. A more sophisticated filtering of postglacial rebound was by using consistently modelled sets of glacial isostatic vertical deformation rates (provided by Andreas Groh ${ }^{1}$ ), based on GIA Model ICE-5G (VM2) of Peltier [46]-ICE-5G is the ice load history and

\footnotetext{
${ }^{1}$ tpg.geo.tu-dresden.de.
}

VM2 is the viscoelastic Earth model-by using the SELEN code which is described in Spada and Stocchi [47].

\subsection{Methods}

\subsubsection{For Different Periods}

(1) Calculation three kinds of the configured linear trends (i.e.: OLS-Trend in term of normality distribution of the regression residuals, GLS-Trend in term of the autocorrelation distribution of the regression residuals, Theil-Sen-Trend in term of nonnormality distribution of the regression residuals) depending on the natural feature of the mean sea level data series at each boreal winter month and season DJF per each studied station, if detected.

(2) Each mean sea level time series what has the linear trend was detrended, by running (OLS-Detrend or GLS-Detrend or Theil-Sen-Detrend). Thus, the residuals represent the detrended mean sea level series.

(3) Estimation the Pearson's correlation coefficients for the interrelations between the detrended mean sea level data series and the NAO indices series of boreal winter months and season DJF per each studied station.

(4) For each significant correlation, the linear regression equation has been calculated strictly for establishing the causation relationship concerning the interrelations mentioned in (3).

(5) The formal regression models have been calculated precisely with percentage error between $0.000 \%-0.001 \%$ by using high accurately techniques for satisfying all regression assumptions like: non-linearity, non-normality, autocorrelation, heteroscedasticity.

(6) The linear trends calculated from (1), represent the relative linear mean sea level trends for each data station over the different data station periods of boreal winter months and season DJF. The climatic trends have been estimated after correcting to the related isostatic trends. 
2.2.2 For the Period 1977-1994 Anomalies

(1) Recalculation the same procedures of calculations that mentioned in the aforementioned points $(1,2,3,4,5)$ from section 2.2.1, over the period 1977 through 1994 for the boreal winter season DJF of the mean sea level anomalies series per each studied station.

(2) Prediction the new detrended mean sea level series anomalies by using the estimated significant linear regression equations that calculated from the previous point as a function of the $\mathrm{NAO}+$ indices anomalies.

(3) Estimation the configured linear trend (i.e.: OLS-Trend, GLS-Trend, Theil-Sen-Trend) for each predicted mean sea level anomalies series that calculated from point (2). Thus the estimated linear trend is the trend caused by the positive phase of the $\mathrm{NAO}+$ index.

2.2.3 Correlation and Regression Coefficients Test Hypotheses

For the correlation and regression coefficients test, a suitable null hypothesis would be that "there is no impact for the NAO+ on the mean sea level during boreal winter months and season timescales over the whole per each data station". On the other hand, a null hypothesis for the linear trend coefficient test would be that "the mean sea level during boreal winter months and season timescales for each data station over the whole period, fluctuate along its constant mean". The analyses will tell if the data are consistent or depart from this expectation. The statistical tests for these coefficients have been calculated at a critical value of the significance level ( $P$-value) according to Smith et al. [48], Cyberski et al. [49], and Kundzewicz and Robson [50], i.e. a $P$-value $\leq 0.05$ indicates statistical significance, but a $P$-value $>0.05$ indicates statistical insignificance.

\section{Results and Discussion}

The impact of the NAO+ index due to its contribution to the configured linear trend of the mean sea level series is expected for different periods. Furthermore, the impact of the $\mathrm{NAO}+$ with its configured linear trend is expected for the 1977-1994 period of the mean sea level series.

\subsection{Results for Different Periods}

\subsection{Results for the Period 1977-1994 Anomalies}

In accordance with previous studies (Alexandersson et al. [52]; Plag and Tsimplis [53]; Johansson et al. [51]; Andersson [21]; Chen and Omstedt [22]; Jevrejeva et al. [23]; Hünicke and Zorita [24]; Hünicke [29]; Johansson [54]), which are not cited in the below text. All these studies confirmed the significant interrelation between the mean sea level and the NAO in boreal winter conditions at the Finnish coast and at the Fennoscandian coasts in the Baltic Sea. Furthermore, they showed a significant increasing linear trend concentrated in the last decades of the 20th century. Also highly correlation was found between the NAO and the mean sea level in the Stockholm tide gauge in Sweden [21], and with temperature anomalies in Sweden and Copenhagen as well [18, 19]. Johansson [54] confirmed that the variations in the winter (December-March) mean NAO index were shown to explain 37-46 per cent of the interannual mean sea level variability at the Finnish coast.

The impacts of the NAO+ on the mean sea level have been detected in the studied stations ( $\mathrm{St} 1, \mathrm{St} 2$, St3) in the boreal winter months and season for different periods (Figs. 1 and 2), and for the 1977-1994 period in the boreal winter season (Fig. 3), respectively.

The correlations and regression coefficients, i.e. under the impact of the $\mathrm{NAO}+$, are high and statistically significant and spatially non-uniform in boreal winter months for different periods, referring to the differences in the strength of the westerly winds as well as the other processes associated with $\mathrm{NAO}+$ at the different stations in accordance with Hünicke and Zorita [24]. Thus, the NAO is responsible for the non 


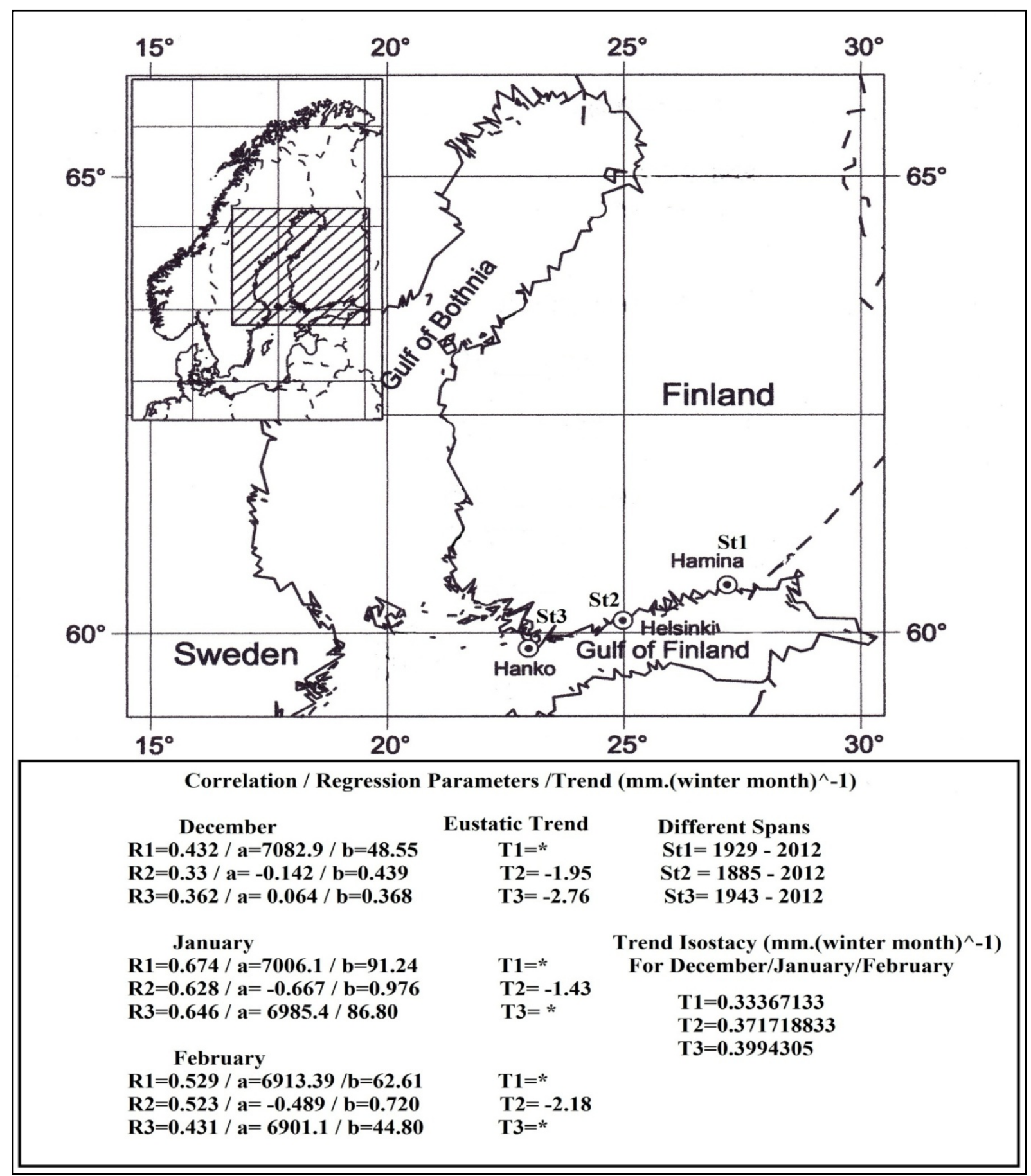

Fig. 1 Map of special classifications of correlation coefficients (R), regression parameters (a, b) between Jones's monthly mean of the NAO indices, and linearly detrended mean sea level series in boreal winter months (December, January, and February) for different periods at the Gulf of Finland coast. (T) Linear Trend coefficients in boreal winter months of mean sea level series for different periods, which it is in $\left.(\mathrm{mm} \text {. (winter month) })^{-1}\right)$. (T) Represents the eustatic or climatic linear trend with contributions of the NAO+. The asterisk (*) indicates to the insignificant trend. Map source Johansson et al. [51]. 


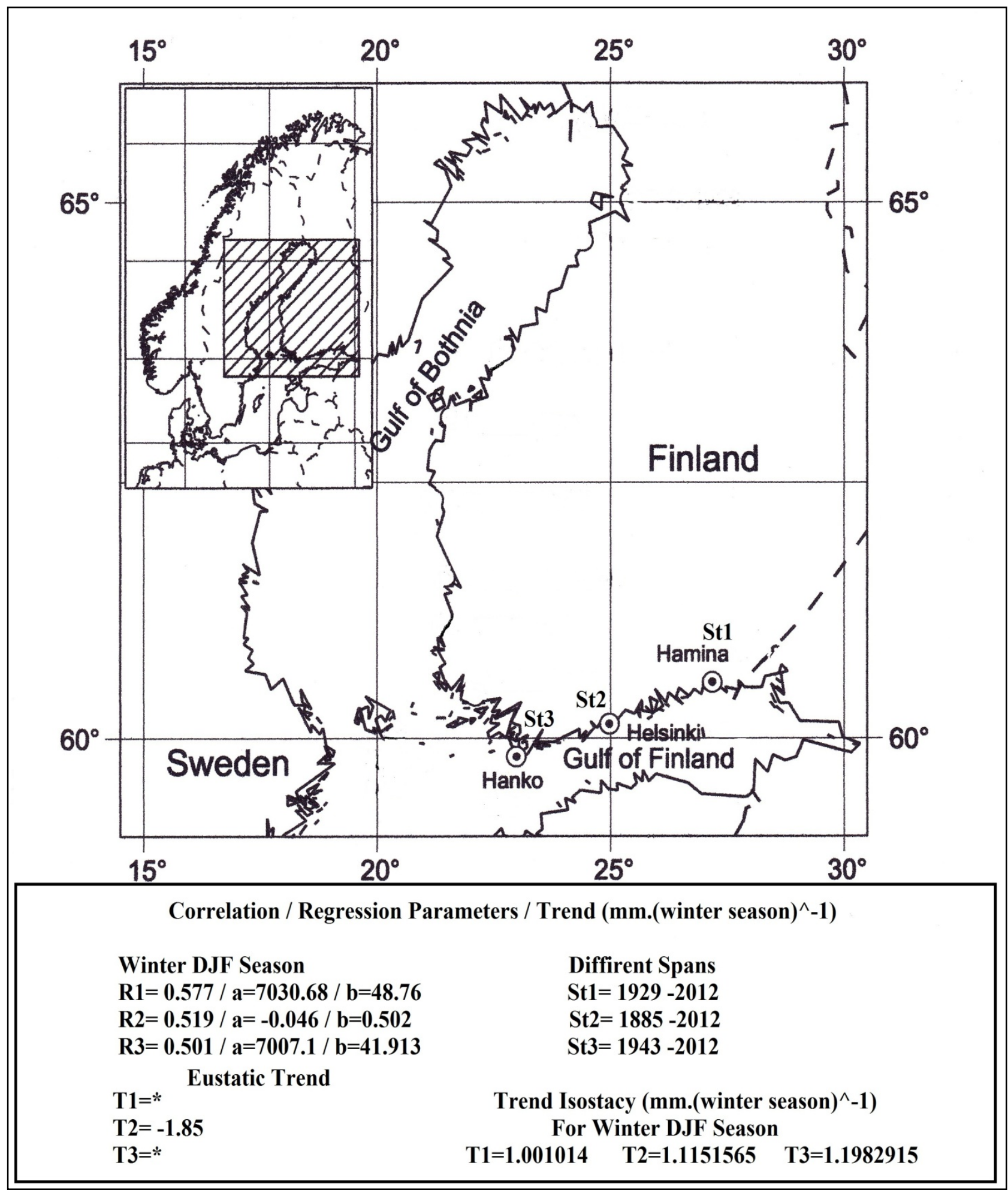

Fig. 2 Map of special classifications of correlations coefficients (R), regression parameters (a, b) between Hurrell's winter season DJF mean of NAO indices, and linearly detrended mean sea level series in boreal winter season DJF for different periods at the Gulf of Finland coast. (T) Linear trend coefficients in boreal winter DJF mean sea level series for different periods, which are in $\left.(\mathrm{mm} \text {. (winter season) })^{-1}\right)$. (T) Represents the eustatic or climatic linear trend with contributions of the NAO+. The asterisk (*) indicates to the insignificant trend. 


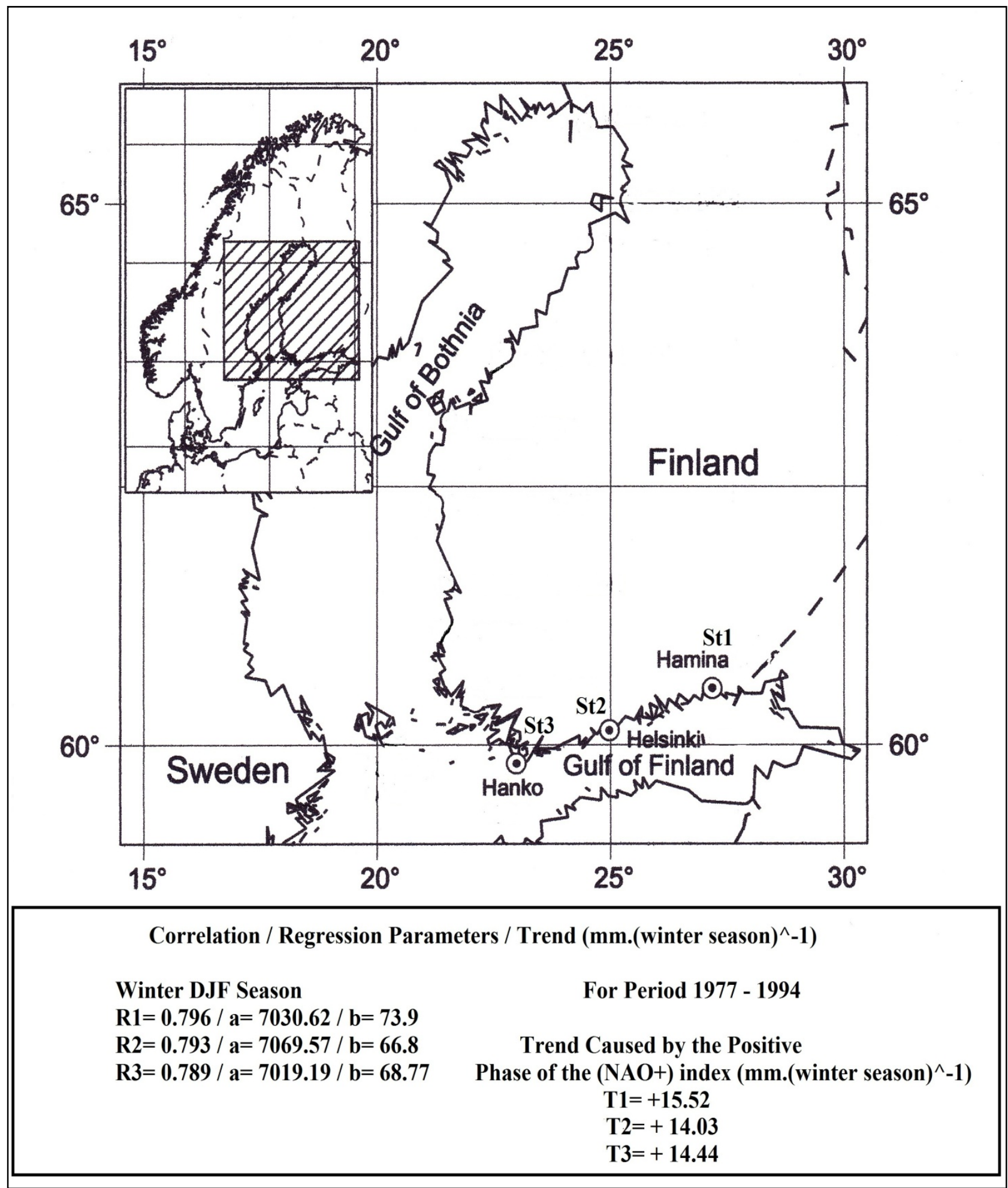

Fig. 3 Map of special classifications of correlations coefficients (R), regression parameters (a, b) between Hurrell's winter season DJF mean of NAO indices, and linearly detrended mean sea level anomalies series in winter season DJF in the Gulf of Finland for the 1977-1994 period. (T) Linear trend coefficients in winter DJF mean sea level anomalies series for the 1977-1994 period, which is in $\left.(\mathrm{mm} \text {. (winter season) })^{-1}\right)$. (T) Represents the trend cause by the NAO+ index. 
uniform patterns of westerly winds, precipitation and temperature as well as rivers discharges changestend to keep the Baltic Sea mean sea level high during winter [51, 55].

However, in the boreal winter season the coefficients are high and statistically significant and almost spatially uniform with different stations. A homogeneous pattern of the correlation in the boreal winter season was detected for the 1997-1994 period within the NAO+ in accordance with Hurrell [3, 4].

The results confirm that the westerly winds, air temperature and precipitation changes were highest in winter when the difference between the regional climate and the climate of the surrounding areas was largest and the atmospheric circulation was strong. Thus, that may lead to the fact that the precipitation contributes heavily to the mean sea level rise in accordance with [56], in which these studies confirmed that the NAO is of major importance for precipitation conditions in Scandinavia and the Baltic Sea during winter.

The existence of the linear trends in boreal winter months and seasons of mean sea level series have been detected at the studied stations (Figs. 1 and 2) for different periods (but not for all stations). These linear trend coefficients that show the significant correlations and regression coefficients which represent the linear trend are configured with the impacts of the climate conditions with the contributions of the NAO+ and the vertical land movement VLM, i.e., due to GIA. Spatially non-uniform and statistically significant findings of linear trends, i.e., referring to the different climate conditions at different stations. Sporadic pattern of positive significant responses are apparent in terms of respective boreal winter months at specific stations can be explained by milder boreal winters (Figs. 1 and 2). Negative linear trends in boreal winter mean sea level can be explained by the influence of the vertical crustal movement due to glacier isostatic adjustment from the melting Scandinavian ice sheet in the early
Holocene at the Finnish coast in the Gulf of Finland.

However, the insignificant trend coefficients that showed the significant correlation coefficients, could be explained from the time series theory [57-59]. Where, a statistically significant correlation between NAO and mean sea level does not necessarily mean there is a "cause" and "effect" relationship between these variables, very weak, where this correlation because of the presence of the low frequency components in the time series such as seasonal and cyclical components.

Therefore, the significant correlations for the impacted stations (St1 and St3 in Figs. 1 and 2) with the NAO indices does not mean there is a linear trend that configured in the mean sea levels series for these stations under the influence of NAO, but the mean sea level fluctuation at each station might be under the influence of lasting multi-decadal wet and dry periods, in which they have different periods from one station to another, and which might correspond with the similar periods that are found in the NAO spectrum.

That is consistent with Hurrell and Van Loon [18] identified significant variance in the boreal winter $\mathrm{NAO}+$ at biennial periods and for 6-10 years. As well as, numerous authors have examined the spectrum of the NAO indices; Hurrell et al. confirmed that the spectrum of the winter mean NAO index is slightly enhanced variance at quasi-biennial periods and for 8-10 years. Thereafter, Andersson showed that peaks, with periods of 2.2-2.3, 5-6, and 7-8 years, appeared in the cross-coherency spectra of the boreal winter NAO index and the Baltic Sea level. These peak periods have also been identified in various other climatological and hydrological time series $[3,18,19$, 20, 60-62].

While, for the 1977-1994 period the existence of the linear trends in boreal winter season DJF of mean sea level anomalies series have been detected at all stations (St1, St2, St3) (Fig. 3), these linear trend coefficients represent a trend that is configured by the impacts of the $\mathrm{NAO}+$ throughout this period what 
calculated after correcting the mean sea level series for the winter NAO+. Spatially uniform positive linear trends, which are around $14 \mathrm{~mm}$ (winter season) ${ }^{-1}$, and statistically significant due to the predominating the $\mathrm{NAO}+$ at these different stations during winter showing strong westerly winds, high temperature, high precipitation that is strongly related to the strong $\mathrm{NAO}+$ during this period. Where, almost of the local warming across Europe and downstream over Eurasia since the mid-1970s can be linearly related to changes in the NAO [18].

In this respect, the change in the local pattern temperatures (surface land, sea surface), based on the linear regression relationship with Hurrell's winter NAO index across the middle and high latitudes of the Northern Hemisphere had been estimated for this period $[4,18]$, and the change was $0.10^{\circ} \mathrm{C}$. winter ${ }^{-1}$.

So, the realistic linear mean sea levels trends that found from the Gulf of Finland coastal stations showing the global warming was more pronounced over the coast. Thereby, the linear trends calculations are very important for the coastal mean sea levels for detecting the anthropogenic climate change and NAO change. That is consistent with the findings of the Bengtsson [63] and Omsted et al. [64] for the European near-surface temperature over the past 500 years when they found the warming trend was appearing as the accumulation of the warmest seasons over the last decades of the last century only causing by the increasing of the greenhouse gases.

It can be concluded that the large-scale westerly winds component over the North Atlantic has a significant effect on sea level oscillations at the Gulf of Finland coast, through the NAO+ influence.

Obtaining the significant trends for the short period 1977-1994, may expect to be very difficult especially the significant relationship between all details of the large scale atmospheric circulation NAO and the coastal mean sea level, since the NAO contain information about many oceanic-atmospheric processes affect the mean sea level change. However, the realistic linear mean sea level trend in the present study was found after the winter mean sea level time series were corrected for the winter $\mathrm{NAO}+$ index within the significant standard ordinary bivariate linear regression relationship considering this phase as a major forcing for mean sea level change. That is, the strong winter positive of $\mathrm{NAO}+$ enhanced as a zonal circulation over the northern Europe supporting the strong westerly winds which brought about more frequent advection of warm and wet Atlantic air masses reinforced this zonal circulation $[65,66]$.

In this regard, there are many studies estimated the linear trend for the coastal mean sea level as a function of the station-based of NAO index during winter season for different periods in northern Europe seas by using simple linear OLS regression like: Tsimplis et al. [66], estimated the linear mean sea level trend as a function of the station-based of NAO index for studying the influence of NAO on long-term winter mean sea level trends for different tide gauges in northern Europe seas by using statistical analyses and they found that the NAO is a major forcing for mean sea level variability. Then, Dangendorf et al. [67] estimated the linear mean sea level trend as a function of the station-based of NAO index also for studying the influence of NAO on long-term, 1937-2008 and 1951-2008, and short-term, 1971-2008, periods of winter mean sea level trends in the German Bight, in which these trends were found after correcting the winter mean sea level time series for the NAO index by applying the simple linear regression models. The results for the trends showed smaller values for the long-term series, but higher values for the short-term series such as for the entire German Bight-North sea, the trends were found to be $7.6 \mathrm{~mm}$.winter ${ }^{-1}, 8.4$ mm.winter ${ }^{-1}, 6.9$ mm.winter ${ }^{-1}$ for the German Bight, Schleswig-Holstein and Lower Saxony virtual stations respectively.

It has to be clear the presented results are not limited to NAO only. For example, the air temperatures especially over the Baltic Sea also 
display discernible trends in the 20th century what caused by the influence of the global warming and could also affect the winter mean sea level rate.

An important thing, is weather the detected linear trend of the positive phase of the $\mathrm{NAO}+$ during 1977-1994 can be extended into the future. That may lead to changes can be happened in mean sea levels patterns at the study region.

Results of the global climate models [68] driven by different scenarios of anthropogenic greenhouse gas forcing and anthropogenic tropospheric aerosols indicate that dry season precipitation will likely increase in northern Europe. The simulated trends are consistent with the trends observed in the twentieth century. If a causal link between the NAO and greenhouse gas forcing can be established, that may lead to increasing the NAO impact on the mean sea level, which enhances the winter linear trend of the mean sea level at the Gulf of Finland coast in the next decades.

The analyses presented here should be understood as complementary to modelling studies. Simulations with a regional model of the Baltic Sea [69] can help to falsify or confirm these hypotheses.

\section{Conclusions}

Since the significant responses of the correlation coefficients were revealed, the winter positive phase of the NAO+ index manifests its linear impact on the coastal mean sea levels of the studied coastal stations during boreal winter months and season over the periods, (i.e., different periods, 1977-1994). The seacoasts revealed the direct impact of the $\mathrm{NAO}+$ manifested by (the westerly winds and the other processes) leading to rising the mean sea levels. Since the linear trends coefficients that are showed the significant correlation coefficients revealed simultaneously for the same mean sea level series, the positive phase of the $\mathrm{NAO}+$ manifests its contribution on the configured linear trend during boreal winter months and season over the periods, (i.e.: different periods). Since the significant responses of the correlation coefficients were revealed during winters of the period 1977-1994, the positive phase of the $\mathrm{NAO}+$ manifests its linear impact on the coastal mean sea levels changes and on the configured linear trend.

The regions of Gulf of Finland coasts were the warmest regions in the context of the realistic portion of the global warming during the winters of the period 1977-1994. The influence of winter NAO+ that causing winter mean sea levels changes is a typical indication for brought strong advection of warm and wet Atlantic air masses in the context of the global warming.

The quantitative differences in significant correlation coefficients for the (mean sea level and $\mathrm{NAO}$ ) interrelations indicate the differences in the strength of the westerly winds as well as in the other processes at the different stations. The quantitative differences in the linear trends coefficients of the mean sea levels series are caused by the differences in the vertical land movement VLM, i.e. due to GIA, and the differences in the processes that controlled by climatic conditions. The significant positive linear changes for mean sea levels are typical indication of the milder winters. However, the significant negative linear changes are the typical indication of the influences of the vertical land movement VLM, i.e. due to GIA.

The mean sea levels that have significant correlations with NAO and showed insignificant trends are typical indications of lasting multi-decadal wet and dry periods associated with NAO spectrum.

Coastal mean sea levels changes could be considered as indicators of the influences of the NAO, the North Atlantic Ocean as well as the realistic portion of the global warming forcing associated with $\mathrm{NAO}$, and the global warming in winter. The present result so may expect to be preserved also in the future when the change for the positive phase of NAO+ happen. The global warming was more pronounced over the Gulf of Finland coasts than due to the 
predominating the influence of the winter $\mathrm{NAO}+$ during the period 1977-1994.

\section{Future Work}

It would also be interesting to investigate the upwelling in the Gulf of Finland under the influences of NAO+ in boreal winter only during the 1977-1994 period by establishing a statistical relationship, for evaluating the global warming impact on this process. Upwelling is a typical phenomenon in the Baltic Sea, including the Gulf of Finland. As the Baltic Sea is a semi-enclosed basin, winds from favourable directions blowing predominately parallel to the coast cause upwelling, leading to vertical displacement of the water body [70].

\section{References}

[1] IPCC Intergovernmental Panel on Climate Change. 2007. Climate Change 2007: The Physical Science Basis, Contribution of Working Group I to the Fourth Assessment of the Intergovernmental Panel on Climate Change. United Kingdom: Cambridge University Press Cambridge.

[2] Thompson, D. W. J., Wallace, J. M., and Hegerl, G. C. 2000. "Annular Modes in the Extratropical Circulation, Part II: Trends.” J. Climate 13: 1018-36.

[3] Hurrell, J. W. 1995. "Decadal Trends in the North Atlantic Oscillation: Regional Temperatures and Precipitation.” J. Science 269 (5224): 676-9.

[4] Hurrell, J. W. 1996. "Influence of Variations in Extratropical Wintertime Teleconnections on Northern Hemisphere Temperature." Geophys. Res. Lett. 23: 665-8.

[5] Graf, H. F., Perlwitz, J., Kirchner, I., and Schult, I. 1995. "Recent Northern Winter Climate Trends, Ozone Changes and Increased Green-House Forcing, Contrib." Atmos. Phys. 68: 233-48.

[6] Thompson, D. W. J., and Wallace, J. M. 1998. "The Arctic Oscillation Signature in the Wintertime Geopotential Height and Temperature Fields." Geophysical Research Letters 25 (9): 1297-300.

[7] Thompson, D. W. J., and Wallace, J. M. 2000. "Annular Modes in the Extratropical Circulation. Part I: Month-to-Month Variability." J. Climate 13: 1000-16.

[8] Mitchell, R., Davis, A., Ingram, W. J., and Senior, C. A. 1995. "On Surface Temperature, Greenhouse Gases, and Aerosols: Models and Observations." J. Climate 8: 2364-86.

[9] Cubasch, U., Hegerl, G. C., and Waszkewitz, J. 1996.
"Prediction, Detection and Regional Assessment of Anthropogenic Climate Change." Geophysica 32: 77.

[10] (Coauthors) Kattenberg, A. 1996. "Climate Models-Projections of Future Climate." Climate Change 1995. The Second Assessment Report of the IPCC. J. T. Houghton et al., Eds., Cambridge University Press, 285-359.

[11] Mitchell, J. F. B., and Johns, T. J. 1997. "On Modification of Global Warming by Sulfate Aerosols." J. Climate 10: 245-67.

[12] Hurrell, J. W. Climate Data Guide (CDG): Hurrell North Atlantic Oscillation (NAO) index (station-based) [online]. https://climatedataguide.ucar.edu/climate-data/hurrell-nor th-atlantic-oscillation-nao-index-station-based. (accessed 11 July 2013).

[13] Hurrell, J. W., and Deser, C. 2014. "Northern Hemisphere Climate Variability during Winter: Looking Back on the Work of Felix Exner." Meteorologische Zeitschrift PrePub.

[14] Barnston, A. G., and Livezey, R. E. 1987. "Classification, Seasonality and Persistence of Low-Frequency Atmospheric Circulation Patterns." Mon Weather Rev. 115: 1083-126.

[15] Van Loon, H., and Rogers, J. C. 1978. "The Seesaw in Winter Temperatures between Greenland and Northern Europe. Part I: General Description.” Mon. Wea. Rev. 106: 296-310.

[16] Rogers, J. C. 1990. "Patterns of Low Frequency Monthly Sea Level Pressure Variability (1899-1986) and Associated Wave Cyclone Frequencies." J. Clim. 3:1364-79.

[17] Cayan, D. R. 1992. "Latent and Sensible Heat Flux Anomalies over the Northern Oceans: The Connection to Monthly Atmospheric Circulation.” J. Clim. 5: 354-69.

[18] Hurrell, J. W., and Van Loon, H. 1997. "Decadal Variations in Climate Associated with the North Atlantic Oscillation." Clim. Change 36: 301-26.

[19] Chen, D., and Hellström, C. 1999. "The Influence of the North Atlantic Oscillation on the Regional Temperature Variability in Sweden: Spatial and Temporal Variations." Tellus A 51: 505-16.

[20] Greatbatch, R. J. 2000. "The North Atlantic Oscillation." Stoch Environ Res Risk Assess 14: 213-42.

[21] Andersson, H. C. 2002. "Influence of Long-Term Regional and Large-Scale Atmospheric Circulation on the Baltic Sea Level." Tellus A 54 (1): 76-88.

[22] Chen, D., and Omstedt, A. 2005. "Climate-Induced Variability of Sea Level in Stockholm: Influence of Air Temperature and Atmospheric Circulation." Adv. Atmos. Sci. 22: 655-64.

[23] Jevrejeva, S., Moore, J. C., Woodworth, P. L., and Grinsted, A. 2005. "Influence of Large-Scale 


\section{Quantifying the Mean Sea Level Change at the Gulf of Finland Coast Caused by the Realistic Portion of the Global Warming Forcing}

Atmospheric Circulation on European Sea Level: Results Based on the Wavelet Transform Method." Tellus A 57: 183-93.

[24] Hünicke, B., and Zorita, E. 2006. "Influence of Temperature and Precipitation on Decadal Baltic Sea Level Variations in the 20th Century." Tellus A 58: 141-53.

[25] Jones, P. D., Jonsson, T., and Wheeler, D. 1997. "Extension to the North Atlantic Oscillation Using Early Instrumental Pressure Observations from Gibraltar and South-West Iceland.” Int. J. Climatol 17: 1433-50.

[26] CRU-Climate Research Unit, Jones's NAO Index Data [online]. http://www.cru.uea.ac.uk/. (accessed 11 July 2012).

[27] Holgate, S. J., Matthews, A., Woodworth, P. L., Rickards, L. J., Tamisiea, M. E., Bradshaw, E., Foden, P. R., Gordon, K. M., Jevrejeva, S., and Pugh, J. 2013. "New Data Systems and Products at the Permanent Service for Mean Sea Level.” J. Coast Res. 29 (3): 493-504.

[28] PSMSL - Permanent Service for Mean Sea Level, Tide Gauge Data [online]. http://www.psmsl.org/data/obtaining/. (accessed 20 January 2014).

[29] Hünicke, B. 2008. "Atmospheric Forcing of Decadal Baltic Sea Level Variability in the Last 200 Years: A Statistical Analysis." Doctoral dissertation, University of Hamburg.

[30] Aitken, A. C. 1936. "On Least Squares and Linear Combinations of Observations." Proc. Royal Soc. Edinburgh 55: 42-8.

[31] Sen, P. K. 1968. "Estimates of the Regression Coefficient Based on Kendall's tau.” J. Amer. Stat. Assoc. 63 (324): 1379-89.

[32] White, H. 1980. “A Heteroskedasticity-Consistent Covariance Matrix Estimator and A Direct Test for Heteroskedasticity." Econometrica 48 (4): 817-38. http://www.jstor.org/stable/1912934.

[33] Farmer, J. D., and Sidorowich, J. J. 1987. "Prediction Chaotic Time Series." Phys. Rev. Lett. 59 (8): 845-8.

[34] Isobe, T., Feigelson, E. D., Akritas, M. G., and Babu, G. J. 1990. "Linear Regression in Astronomy." Astrophys. J. I 364: 104-13.

[35] Casdagli, M., des Jardins, D., Eubank, S., Farmer, J. D., Gibson, J., Theiler, J., and Hunter, N. 1992. "Nonlinear Modeling of Chaotic Time Series: Theory and Applications." In Applied Chaos, edited by Kim, J. H., and Stringer, J. New York: Wiley, 335-80.

[36] Navone, H. D., and Ceccatto, H. A. 1995. "Forecasting Chaos from Small Data Sets: A Comparison of Different Nonlinear Algorithms." J. Phys. A 28 (12): 3381-8.

[37] Kugiumtzis, D., Lingjærde, O. C., and Christophersen, N. 1998. "Regularized Local Linear Prediction of Chaotic
Time Series." Physica D 112 (3-4): 344-60.

[38] Green, W. H. 2003. Econometric Analysis, 5th edn. Upper Saddle River(NJ): Prentice Hall.

[39] Gujarati, D. 2003. Basic Econometrics, 4th edn. New York: McGraw-Hill/Irwin.

[40] Yue, S., and Pilon, P. 2004. "A Comparison of the Power of the Test, Mann-Kendall and Bootstrap Tests for Trend Detection." Hydrol. Sci. J. 49 (1): 21-37.

[41] Dagum, E. B., and Dagum, C. 2006. "Stochastic and Deterministic Trend Models." Statistica 66 (3): 269-80.

[42] Pekarova, P., Miklanek, P., and Pekar, J. 2006. "Long-Term Trends and Runoff Fluctuations of European Rivers." In Climate Variability and Change-Hydrological Impacts, edited by Demuth, S., Gustard, A., Planos, E., Scatena, F., and Servat, E. Wallingford(UK): IAHS Press, 520-5.

[43] Zervas, C. 2001. Sea Level Variations of the United States, 1854-1999. Silver Spring, MD.: U.S. Dept. of Commerce, National Oceanic and Atmospheric Administration, National Ocean Service.

[44] Zervas, C. 2009. Sea Level Variations of the United States 1854-2006. Silver Spring, MD.: U.S. Dept. of Commerce, National Oceanic and Atmospheric Administration, National Ocean Service.

[45] Seltman, H. J. 2013. "Experimental Design and Analysis." [online].

http://www.stat.cmu.edu/_hseltman/309/Book/Book.pdf. Accessed 5 April 2014

[46] Peltier, W. R. 2004. "Global Glacial Isostasy and the Surface of the Ice-Age Earth: The ICE-5G (VM2) Model and GRACE." Annu. Rev. Earth Planet. Sci. 32: 111-49.

[47] Spada, G., and Stocchi, P. 2007. "Selen: A Fortran 90 Program for Solving the 'Sea-Level Equation'." Comput. Geosci. 33: 538-62.

[48] Smith, D. G., McBride, G. B., Bryers, G. G., Wisse, J., and Mink, D. F. J. 1996. "Trends in New Zealand's National River Water Quality Network." $N$ Z J Mar Freshw Res 30: 485-500.

[49] Cyberski, J., Wróblewski, A., Stewart, J. 2000. "Riverine Water Inflows and the Baltic Sea Water Volume 1901-1990." Hydrol. Earth Syst. Sci. 4: 1-11.

[50] Kundzewicz, Z. W., and Robson, A. 2000. "Detecting Trend and Other Changes in Hydrological Data." WCDMP-45, WMO/TD-No. 1013. WMO/UNESCO, Geneva.

[51] Johansson, M., Boman, H., Kahma, K. K., and Launiainen, J. 2001. "Trends in Sea Level Variability in the Baltic Sea." Boreal Environ Res 6: 159-79.

[52] Alexandersson, H., Schmith, T., Iden, K., and Tuomenvirta, H. 1998. "Long-Term Variations of the Storm Climate over NW Europe." Glob Atmos. Ocean Syst. 6: 97-120. 


\section{Realistic Portion of the Global Warming Forcing}

[53] Plag, H. P., and Tsimplis, M. N. 1999. "Temporal Variability of the Seasonal Sea-Level Cycle in the North Sea and Baltic Sea in Relation to Climate Variability." Glob Planet Change 20: 173-203.

[54] Johansson, M. M. 2014. "Sea Level Changes on the Finnish Coast and Their Relationship to Atmospheric Factors." Doctoral thesis, University of Helsinki.

[55] Yan, Z., Tsimplis, M. N., and Woolf, D. 2004. "Analysis of the Relationship between the North Atlantic Oscillation and Sea Level Changes in Northwest Europe." Int. J. Climatol. 24: 743-58.

[56] Uvo, C. B. 2003. "Analysis and Regionalization of Northern Europe Winter Precipitation Based on Its Relationship with the North Atlantic Oscillation.” Int. J. Climatol. 23: 1185-94.

[57] Jenkins, G. M., and Watts, D. G. 1968. Spectral Analysis and Its Applications. San Francisco: Holden-Day.

[58] Chelton, D. B. 1982. "Statistical Reliability and the Seasonal Cycle: Comments on 'Bottom Pressure Measurements across the Antarctic Circumpolar Current and Their Relation to the Wind'." Deep Sea Res. A 29: 1381-8.

[59] Emery, W. J., and Thomson, R. E. 2001. Data Analysis Methods in Physical Oceanography. San Diego, CA: Elsevier.

[60] Alenius, P., and Makkonen, L. 1981. "Variability of the Annual Maximum Ice Extent of the Baltic Sea." Arch Meteorol Geophys Bioclimatol B 29:393-8.

[61] Wanner, H., Brönnimann, S., Casty, C., Gyalistras, D., Luterbacher, J., Schmutz, C., Stephenson, D. B., and Xoplaki, E. 2001. "North Atlantic Oscillation-Concepts and Studies." Surv. Geophys 22: 321-81.

[62] Rautio, L. M., Westberg, V., Vilkki, B., Pihlaja, S. 2006. Bernet Catch Theme Report: Public Participation and Water Management in the Baltic Sea Region, Regional
Implementation of the EU Water Framework Directive in the Baltic Sea Catchment. Vaasa: Ykkös-Offset.

[63] Bengtsson, L. 2013. "What is the Climate System Able to Do 'on its own'?" Tellus B 65: 20189. http://dx.doi.org/10.3402/tellusb.v65i0.20189.

[64] Omstedt, A., Elken, J., Lehmann, A., Leppäranta, M., Meier, H. E. M., Myrberg, K., and Rutgersson, A. 2014. "Progress in Physical Oceanography of the Baltic Sea during the 2003-2014 Period." Progress in Oceanography 128: 139-71.

[65] Johansson, M. M., Kahma, K. K., and Boman, H. 2003. "An Improved Estimate for the Long-Term Mean Sea Level on the Finnish Coast." Geophysica 39: 51-73.

[66] Tsimplis, M., Woolf, D., Osborn, T., Wakelin, S., Wolf, J., Flather, R., Shaw, A., Woodworth, P., Challenor, P., and Blackman, D. 2005. "Towards a Vulnerability Assessment of the UK and Northern European Coasts: The Role of Regional Climate Variability." Philos. Trans. Roy. Soc. London Ser. A: Math. Phys. Eng. Sci. 363 (1831): 1329-58.

[67] Dangendorf, S., Wahl, T., Hein, H., Jensen, J., Mai, S., and Mudersbach, C. 2012. "Mean Sea Level Variability and Influence of the North Atlantic Oscillation on Long-Term Trends in the German Bight." Water 4: 170-95.

[68] Giorgi, F., and Bi, X. 2005. "Updated Regional Precipitation and Temperature Changes for the 21st Century from Ensembles of AOGCM Simulations." Geophys. Res. Lett. 32.

[69] Kauker, F., and Meier, H. E. M. 2003. "Modelling Decadal Variability of the Baltic Sea: 2. Role of Fresh Water Inflow and Large-Scale Atmospheric Circulation for salinity." J. Geophys. Res. 108.

[70] Lehmann, A., and Myrberg, K. 2008. "Upwelling in the Baltic Sea-A Review.” J. Mar. Syst. 74: S3-S12. 